\title{
重组枯草芽孢杆菌分泌表达缺陷假单胞菌磷酸 三醌酶及其发酵优化
}

\author{
杨贞妮 ${ }^{1}$, 郭旋 ${ }^{2}$, 钟近艺 $2^{*}$, 辛瑜 ${ }^{1}$, 李由然 ${ }^{1}$, 石贵阳 ${ }^{1}$, 张梁 ${ }^{*}$ \\ 1. 江南大学, 粮食发酵工艺与技术国家工程实验室, 工业生物技术教育部重点实验室, 无锡 214122; \\ 2. 中国人民解放军军事科学院防化研究院, 北京 102205 \\ *联系人, E-mail: linfzjy@163.com; zhangl@jiangnan.edu.cn \\ 收稿日期：2018-12-17; 接受日期：2019-01-25; 网络版发表日期：2019-03-21 \\ 陆军装备预先研究项目(批准号: 30110020401)资助
}

摘要 磷酸三酯酶(phosphotriesterase, PTE, EC3.1.8.1)能够水解有机磷化合物, 但其应用一直受限于酶表达量低 的问题. 为了获得高效表达的有机磷水解酶, 本文构建了PTE基因来源于缺陷假单胞菌(Pseudomonas diminuta)的 重组枯草芽孢杆菌(Bacillus subtilis WB600), 并采用单因素实验和正交实验对培养基进行优化, 确定了重组菌产 酶的最佳发酵条件, 同时检测重组酶对有机磷类化合物的降解作用。结果表明, 最优的培养基组成为蔗糖 $(40 \mathrm{~g} / \mathrm{L})$ 、酵母膏 $(40 \mathrm{~g} / \mathrm{L})$ 、蛋白炼 $(20 \mathrm{~g} / \mathrm{L})$ 、磷酸氢二钾 $(2 \mathrm{~g} / \mathrm{L})$ 、硫酸锰 $(1 \mathrm{~g} / \mathrm{L})$ 、硫酸镁 $(6 \mathrm{~g} / \mathrm{L})$. 经测定，该酶 $4 \mathrm{~h}$ 内对 $(5 \mathrm{mg} / \mathrm{mL}$ 的甲基对硫磷、乐果以及神经毒剂模拟剂甲基磷酸二甲酯(dimethyl methyl phosphonate, DMMP)的 降解率分别达到 $98 \%, 92 \%, 73 \%$, 且DMMP在 $12 \mathrm{~h}$ 内也完全降解. 本文实现了 PTE的胞外分泌表达, 为研制有机磷 化合物的酶基消毒剂提供了技术支持.

关键词磷酸三酯酶, 枯草芽孢杆菌, 发酵条件优化, 有机磷化合物, 降解率

微生物来源的磷酸三酯酶(phosphotriesterase, PTE，EC3.1.8.1 $)^{[1]}$ 可以广泛水解有机磷类杀虫剂及神 经毒剂. 该酶能够断裂磷酯键而使有机磷化合物脱毒, 具有绿色环保和原位解毒优势，为此类有毒化合物提 供了生物解毒新途径. 生物酶的催化反应过程效率 高、特异性强，使其在有机磷类化合物特异性检测、 防护、中毒救治以及污染环境修复方面具有不可忽视 的应用潜力 ${ }^{[2]}$. 目前已经报道的可水解有机磷类化合 物的几种酶包括人源的PON1, 鱿鱼的DFPase以及细 菌的OPAA和磷酸三酯酶 $(P T E)^{[3 \sim 9]}$. 研究表明, 在这些
酶中PTE和PON1对有机磷类化合物具有较强的水解 作用. PTE属于酰胺水解酶超家族成员, 该超家族催化 的反应包括酰胺、酯、糖及有机磷酸酯等的水解; 其 活性位点具有单核或双核金属中心 ${ }^{[10]}$. 目前有机磷水 解酶的表达主要集中在大肠杆菌(Escherichia coli)中, 但表达量低, 远远达不到工业生产水平, 而且所得蛋 白包涵体较多, 可溶性表达不高 ${ }^{[11]}$. 同时, 研究者也利 用MBP(麦芽糖结合蛋白标签), GST(谷胱甘肽颈基转 移酶标签)等标签蛋白来促进可溶性表达, 但这给酶蛋 白的后续应用带来了问题, 需要将标签切除之后才可

引用格式: 杨贞妮, 郭旋, 钟近艺, 等. 重组枯草芽孢杆菌分泌表达缺陷假单胞菌磷酸三酯酶及其发酵优化. 中国科学: 生命科学, 2019, 49: 625-636 Yang Z N, Guo X, Zhong J Y, et al. Recombinant expression and optimization of fermentation conditions of phosphotriesterase (in Chinese). Sci Sin Vitae, 2019, 49: 625-636, doi: 10.1360/N052018-00237 
以使用 ${ }^{[12,13]}$. 蛋白的正确折叠部分依赖于分子伴侣, 有 研究表明通过共表达折叠酶以及分子伴侣可以有效防 止E. coli 中抗体片段的错误折叠和聚集 ${ }^{[14,15]}$. E. coli周 质中含有多种能够协助蛋白质组装及二硫键形成的分 子伴侣蛋白, 最常见的是 Dsb家族蛋白DsbA，DsbB， $\mathrm{DsbC｝ \text {，DsbD及DsbG．共表达周质分子伴侣，如Skp， }}$ FkpA, 可以减少蛋白分泌后的聚集, 同样, 当共表达周 质折叠酶, 如DsbA，DsbC，可以促进分泌蛋白二硫键 的正确形成，提高蛋白的溶解性和产率 ${ }^{[16,17]}$. 2015年, 龚攀等人 ${ }^{[18]}$ 将热稳定性提高的突变体MPH-S274Q在 毕赤酵母中表达，经摇瓶诱导培养 $120 \mathrm{~h}$ 后，培养上清 的酶活力达到 $0.7 \mathrm{U} / \mathrm{mL}$. Dälken课题组 ${ }^{[19]}$ 利用 $\mathrm{MBP}$ 与 人体颗粒酶 $\mathrm{B}$ 融合表达，提高 $\mathrm{Gr} B$ 在毕赤酵母中的分 泌，MBP增加了蛋白可溶性，同时提供了良好的分泌 信号, 以帮助外源蛋白有效地折叠，从而提高了外源 蛋白的表达. Chang等人 ${ }^{[20]}$ 通过构建 7 个不同的 $\mathrm{N}$-端截 短的皱褶假丝酵母脂肪酶突变体, 在毕赤酵母培养 7 天 后，发现截短的LIP2分泌产量提高了 0.5 倍. 作为分泌 异源蛋白的毕赤酵母表达系统虽然具有许多优点，但 是毕赤酵母发酵周期较长(5天左右，是原核表达系统 发酵周期的两倍), 诱导异源基因表达的甲醇对酵母细 胞具有一定的毒性且为易燃危险品，在大规模生产时 存在安全隐患. 此外, 由于信号肽选择的问题也会出 现酵母细胞中有大量的异源重组蛋白难以被分泌到细 胞外 ${ }^{[21,22]}$. 枯草芽孢杆菌作为理想的外源蛋白表达宿 主，特别是在分泌表达方面有其特有的优势，Yang等 人 ${ }^{[23]}$ 利用双精氨基酸运输机制(Tat途径)提高MPH的 分泌, 将大肠杆菌的三甲胺氧化还原酶(Tor A)双精氨 酸信号肽与MPH在枯草芽孢杆菌中共表达, MPH的分 泌量为 $6.1 \mathrm{mg} / \mathrm{L}$, 此表达量距离酶的实际应用量还有 一定距离.

本研究构建的重组表达载体 $\mathrm{pHY}-\mathrm{ZL}$ 是以地衣芽 孢杆菌高温淀粉酶基因为强启动子和信号肽控制外源 基因的分泌表达. 将目前研究报道的几个主要的有机 磷水解酶基因在枯草芽孢杆菌中进行了重组表达，按 照GJB3638-1999《消毒效果评价方法》，利用粗酶液 评价酶液对神经毒剂模拟剂——基磷酸二甲酯( dimethyl methyl phosphonate, DMMP)的消毒效果, 笁选 并确定了降解效率最高的酶基因作为研究对象，并进 一步对该酶的表达条件进行优化，以期获得高效表达 的PTE, 为酶的实际应用奠定基础. 本研究的重组酶在
有机磷类化合物的降解方面具有较大的应用潜力，不 仅可以用于有机磷类化合物中毒的防护、消毒和人员 救治, 同时也可以用于痕量有机磷农药残留的检测.

\section{1 材料与方法}

\section{1 材料}

(1) 菌株、质粒和培养基. 本研究所用菌株和质粒 及其相关性如表 1 所示. LB培养基 $(\mathrm{g} / \mathrm{L})$ : 蛋白胨 10 , 酵 母粉 5 , 氯化钠 $10,1 \times 10^{5} \mathrm{~Pa}$ 高压蒸汽灭菌 $20 \mathrm{~min}, \mathrm{LB}$ 固 体培养基另加入 $2 \%$ 的琼脂粉. 枯草芽孢杆菌转化培养 基 $(\mathrm{g} / \mathrm{L})$ : spI-a溶液: $\left(\mathrm{NH}_{4}\right)_{2} \mathrm{SO}_{4} 4, \mathrm{~K}_{2} \mathrm{HPO}_{4} \cdot 3 \mathrm{H}_{2} \mathrm{O} \quad 28$, $\mathrm{KH}_{2} \mathrm{PO}_{4} 12$, 二水合柠檬酸钠 2.0; spI-b溶液: $\mathrm{MgSO}_{4}$ • $7 \mathrm{H}_{2} \mathrm{O}$ 0.4; 萄糖溶液 $(\mathrm{w} / \mathrm{v}): 50 \%$ 无水葡萄糖; $100 \times \mathrm{CAYE}$ 溶液: 酪蛋白氨基酸 20.0 , 酵母粉 $100.0 ; \mathrm{CaCl}_{2}$ 溶液: $50 \mathrm{mmol} / \mathrm{L} \quad \mathrm{CaCl}_{2} ; \mathrm{MgCl}_{2}$ 溶液: $250 \mathrm{mmol} / \mathrm{L} \mathrm{MgCl}_{2}$; $100 \times$ EGTA溶液: $10 \mathrm{mmol} / \mathrm{L}$ EGTA, 溶解时用 $\mathrm{NaOH}$ 溶 液调节 $\mathrm{pH}$ 至 8.0 , 过滤除菌于 $-20^{\circ} \mathrm{C}$ 冷藏备用.

(2) 主要试剂. 限制性内切酶和TaqDNA聚合酶购 自Fermentas公司(美国); 质粒小量提取试剂盒、DNA 片段纯化试剂盒和胶回收试剂盒购自康宁生命科学有 限公司(上海); T4 DNA连接酶和DNA Marker购自 Takara公司(日本), 牛血清蛋白购自国药集团化学试剂公 司(上海), 甲基对硫磷、乐果购自上海农药研究所, 对 硝基苯酚购自北京万佳首化生物科技有限公司, 氨芐 青霉素和四环素购自上海生物工程股份有限公司, 其 他试剂均为国产分析纯.

\section{2 重组枯草芽孢杆菌表达载体的构建}

按照枯草芽孢杆菌密码子偏爱性进行优化合成 $u r b, p c n, o b 3, o p h, m p d, o p h c 2$, 以合成的基因为模板, 分别用表2引物扩增基因序列, 引物的两端引入 EcoR I /Kpn I，T/A克隆进pMD19-T Simple Vector, 分别命名为pMD19-T-urb, pMD19-T-pcn, pMD19-Tob3, pMD19-T-oph, pMD19-T-mpd, pMD19-T-ophc2. 测序正确后, 采用 $E c o \mathrm{R}$ I / Kpn I 对其进行酶切, 切胶 回收目的片段, 将经EcoR I / Kpn I 线性化的载体pHYZL与经EcoR I /Kpn I 消化的pMD19-T-urb, pMD19-Tpcn, pMD19-T-ob3, pMD19-T-oph, pMD19-T-mpd, pMD19-T-ophc2 的片段, 按照质量比 1:10的比例加入 $10 \mu \mathrm{L}$ 体系中, 于 $16^{\circ} \mathrm{C}$ 培养箱连接过夜, 转入 B. subtilis 
表 1 质粒与菌株

Table 1 Plasmids and strains

\begin{tabular}{ccc}
\hline 质粒与菌株 & 作用和特点 & 来源 $^{\text {. }}$ \\
\hline JM109 & E. coli, wild type & 本实验室 \\
pMD19-T & Cloning vector, Amp ${ }^{\mathrm{r}}$ & 本实验室 \\
pHY-ZL & Bacillus-E.coli shuttle vector, Amp ${ }^{\mathrm{r}}$ and $\mathrm{Tet}^{\mathrm{r}}$ & 本实验室 \\
$\mathrm{pHY}$-ZL-ob3 & PHY-ZL based vector, carrying ob3 gene, Tet $^{\mathrm{r}}$ & 本研究 \\
WB600 & Bacillus subtilis, wild type & 本实验室 \\
\hline
\end{tabular}

表 2 本研究使用的引物

Table 2 Primers used in the present study

\begin{tabular}{|c|c|}
\hline 基因 & 引物序列 \\
\hline \multirow{2}{*}{ oph } & 5'-3'CCGGAATTCATGGATCGTATTAACACCGTGCG \\
\hline & 5'-3'CGGGGTACCCTATTATCAATGGTGATGGTGATGATGGCGCAGCGTCGGCGATAAAAAA \\
\hline \multirow{2}{*}{$u r b$} & 5'-3'CCGGAATTCATGGATAGAATTAATACAGTTAGAGGCCCG \\
\hline & 5'-3'CGGGGTACCCTATTATCAATGGTGATGGTGATGATGTGTCGGGCTCAGAAATCTTGCCGGAT \\
\hline \multirow{2}{*}{ pcn } & 5'-3'CCGGAATTCATGGGCGATAGAATTAATACAGTTAGAGGC \\
\hline & 5'-3'CGGGGTACCCTATTATCAATGGTGATGGTGATGATGGCTTGCTCTCAGTGTCGGGCTCAGAA \\
\hline \multirow{2}{*}{ mpd } & 5'-3'CCGGAATTCATGAGCATTGGCACAGGCGA \\
\hline & 5'-3'CGGGGTACCCTATTATCA ATGGTGATGGTGATGATG TGATGCTCTCAGTGTCGGG \\
\hline \multirow{2}{*}{$o b 3$} & 5'-3'CCGGAATTCATGGATAGAATTAATACAGTTAGAGGACCG \\
\hline & 5'-3'CGGGGTACCCTATTATCAATGGTGATGGTGATGATGTGCTCTAAGTGTCGGTGACAGAAA \\
\hline \multirow{2}{*}{ ophc2 } & 5'-3'CCGGAATTCATGGGAGATAGAATTAATACAGTTAGAGGC \\
\hline & 5'-3'CGGGGTACCCTATTATCAATGGTGATGGTGATGATGCTCGCTCTCAGTGTCGGGCTCAGAAA \\
\hline
\end{tabular}

WB600, 涂布四环素抗性平板, 挑取转化子, 提取质粒, 经EcoR I / Kpn I 酶切验证, 得到构建成功的重组载体.

\section{3 有机磷水解酶的篮选}

按照GJB3638-1999《消毒效果评价方法》，评价 粗酶液对神经毒剂模拟剂—甲基磷酸二甲酯的消毒 效果, 篮选并确定降解效率最高的酶基因作为研究 对象.

\section{4 酶活力的测定}

本研究以甲基对硫磷为底物，通过检测磷酸三酯 酶对其降解作用来测定重组酶活性. 在甲基对硫磷的 降解过程中, 甲基对硫磷的消耗量与其降解产物对硝 基苯酚的生成量之间为 $1: 1$ 的关系, 所以本研究通过检 测产生的对硝基苯酚的量而得到甲基对硫磷被降解 的量.
甲基对硫磷水解酶酶活性测定参照邓敏捷课题 组 ${ }^{[24]}$ 的方法: 取 $100 \mu \mathrm{L}$ 待测酶液加入到含有 $5 \mu \mathrm{L}$ $10 \mathrm{mg} / \mathrm{mL}$ 甲基对硫磷和 $900 \mu \mathrm{L} 50 \mathrm{mmol} / \mathrm{L}$ Tris- $\mathrm{HCl}$ $(\mathrm{pH}=8.0)$ 的反应体系中, $37^{\circ} \mathrm{C}$ 反应 $10 \mathrm{~min}$, 加入 $1 \mathrm{~mL}$ $10 \%$ 的 TCA 终止液, 再加入 $1 \mathrm{~mL} 10 \%$ 的 $\mathrm{Na}_{2} \mathrm{CO}_{3}$ 溶液显 色, $410 \mathrm{~nm}$ 测定吸光值 $A_{410}$, 计算水解产物对硝基酚的 含量和酶活性. 其中甲基对硫磷水解酶酶活性的定义 为: 在上述条件下, 每分钟释放 $1 \mu \mathrm{mol}$ 对硝基酚所需要 的酶量为 1 个酶活单位 $(\mathrm{U})$.

\section{5 重组酶的纯化分析}

将重组枯草芽狍杆菌接种于 $20 \mathrm{~mL} \mathrm{LB}$ 液体培养 基中，接种量 $4 \%$, 四环素终浓度为 $20 \mathrm{ug} / \mathrm{mL}, 37^{\circ} \mathrm{C}$ 培 养20 h. 离心收集上清, 即为粗酶液, 其用于镍柱亲和 层析. HisTrap ${ }^{\mathrm{TM}} \mathrm{HP}$ 纯化操作: 上样开始先用 $15 \mathrm{~mL} \mathrm{~A}$ 液冲洗亲和柱. 进样量 $40 \mathrm{~mL}$, 进样时流速为 $1 \mathrm{~mL} / \mathrm{min}$, 
进样结束后, 先用 $30 \mathrm{~mL} \mathrm{~A}$ 液洗脱杂蛋白, 再以 $20 \mathrm{~mL}$ B液线性洗脱重组蛋白, B液的浓度从 $0 \sim 100 \%$, 收集蛋 白峰. 最后用 $10 \mathrm{~mL}$ A液平衡亲和柱，流速一直保持 $1 \mathrm{~mL} / \mathrm{min}$. HiPrep ${ }^{\mathrm{TM}} 26 / 10$ Desalting纯化操作步骤: 所 得蛋白峰用HiPrep ${ }^{\mathrm{TM}} 26 / 10$ Desalting柱脱去高浓度的 咪唑. 进样量为 $5 \mathrm{~mL}$, 进样前预先用 2 倍柱体积的超纯 水平衡, 进样后以 1.5 倍柱体积去离子水洗脱蛋白, 收 集得到蛋白峰, 即为除去咪唑的PTE纯蛋白. 得到的蛋 白峰用SDS-PAGE分析 ${ }^{[25]}$.

A液： $25 \mathrm{mmol} / \mathrm{L}$ Tris- $\mathrm{HCl}(\mathrm{pH} 7.4), 0.5 \mathrm{~mol} / \mathrm{L}$ $\mathrm{NaCl}, 20 \mathrm{mmol} / \mathrm{L}$ 咪唑; B液: $25 \mathrm{mmol} / \mathrm{L}$ Tris- $\mathrm{HCl}(\mathrm{pH}$ 7.4), $0.5 \mathrm{~mol} / \mathrm{L} \mathrm{NaCl}, 500 \mathrm{mmol} / \mathrm{L}$ 咪唑.

\section{6 重组蛋白的SDS-PAGE分析}

将构建的重组菌WB600/pHY-ZL-ob3和WB600/ pHY-ZL 接种于 $50 \mathrm{~mL}$ 液体 $\mathrm{LB}$ 培养基中, $37^{\circ} \mathrm{C}$, $200 \mathrm{r} / \mathrm{min}$ 培养 $20 \mathrm{~h}$ ，将发酵液于 $12000 \mathrm{r} / \mathrm{min}$ 离心 $5 \mathrm{~min}$, 取上清进行SDS-PAGE分析.

\section{7 培养基优化}

(1) 单因素法确定各因素中心点. 考察因素如表3 所示. 通过测定酶活和菌体生长量来判断这些因素对 菌体生长和产酶的影响, 在以下实验中每个因素做 3 个平行, 取其平均值. 摇瓶培养条件为: 初始 $\mathrm{pH} 7.0$, 接种量为 $4 \%, 250 \mathrm{~mL}$ 锥形瓶中装液量为 $50 \mathrm{~mL}, 37^{\circ} \mathrm{C}$, 200 r/min培养 $20 \mathrm{~h}$.

( i ) 碳源对重组菌生长和产酶的影响. 以LB培养 基为基础培养基, 其他条件不变, 碳源添加量为 $2 \%$, 氮 源为 $1.5 \%$ 的蛋白胨十酵母粉 $(2: 1)$. 选择最佳碳源; 优化 最佳碳源的浓度, 其添加量设定为 $0.5 \% \sim 5.0 \%$.

(ii) 氮源对重组菌生长和产酶的影响. 氮源添加
量为 $3 \%$, 在上述碳源的结果上, 获得最佳的氮源, 同时 探究最佳复合氮源比例, 其比例分别设定为 $3: 0,5: 1$, $2: 1,1: 1,1: 5,1: 2,0: 3$, 探究最佳氮源添加量, 设定为 2\% 8\%, 其他条件不变.

(iii) 无机盐对重组菌的生长和产酶的影响. 无机 盐添加量为 $2 \mathrm{~g} / \mathrm{L}$, 以优化好的碳源为基础, 以不添加 无机盐的培养基为对照. 同时研究了最佳无机盐浓度 的添加量, 其他条件不变.

(iv) 不同金属离子对重组菌产酶的影响. 在上述 要优化的碳氮源和无机盐的基础上，金属离子添加量 为 $0.5 \mathrm{~g} / \mathrm{L}$, 以不添加其他金属离子的培养基为对照. 同时探究最佳金属离子的添加量, 其选择范围为 $1 \sim 6 \mathrm{~g} / \mathrm{L}$, 其他条件不变.

(2) 正交实验. 通过以上因素的探究, 采用 $\mathrm{L}_{18}\left(3^{7}\right)$ 进行六因素三水平的正交实验(表4), 选择一个最佳的 培养基组合.

(3) 优化结果验证实验. 培养条件不变, 将重组菌 分别接入优化前后的培养基中进行培养, $20 \mathrm{~h}$ 后测定 $A_{600}$ 和重组酶活性, 进行优化后结果验证.

\section{8 重组酶对有机磷化合物降解率的测定}

考察不同反应时间 $(1,2,4,6,8,12,24 \mathrm{~h})$ 下重组酶 对甲基对硫磷、乐果、DMMP的催化降解性能：反应 温度 $37^{\circ} \mathrm{C}$, 在试管中进行催化消毒实验, 其中酶的用 量 $10 \mathrm{mg}$, 底物用量 $5 \mathrm{mg}$; 反应结束时用 $2 \mathrm{~mL}$ 二氯甲烷 萃取, 萃取液用Agilent 7890 A气相色谱(FID检测器, 检 测限为 $1.8 \times 10^{-11} \mathrm{~g} / \mathrm{s}$ ) 分析, 根据反应前后峰面积的比 值定量分析反应物的转化率. 使用 $2 \mathrm{~mL}$ 二氯甲烷萃取 $1 \mathrm{~mL}$ 自然水解不同时间点的有机磷化合物作为标准 样计算降解率, 每个样品分别测定三个平行样并取其 平均值作为最终结果 ${ }^{[26]}$.

表 3 培养基成分考察因素

Table 3 Culture media components

\begin{tabular}{|c|c|}
\hline 因素 & 种类 \\
\hline 碳源 & $\begin{array}{c}\text { A: 甘油; B: 葡萄糖; C: 半乳糖; D: 乳糖; E: 麦芽糖; F: 蔗糖; G: 玉米粉; H: 可溶性淀粉; } \\
\text { I: 麸皮; J: 马铃薯淀粉; K:糊精 }\end{array}$ \\
\hline 氮源 & $\begin{array}{l}\text { A: 蛋白胨; B: 胰蛋白胨; C: 牛肉膏; D: 酵母膏; E: 酵母粉; F: 硫酸铵; G: 硝酸钾; H: 蛋白胨+硫酸铵 }(2: 1) ; \mathrm{I}: \text { 蛋白胨+硝酸钾 } \\
(2: 1) ; \mathrm{J}: \text { 酵母粉+硫酸铵 }(2: 1) ; \mathrm{K}: \text { 酵母粉+硝酸钾 }(2: 1) ; \mathrm{L}: \text { 蛋白胨+酵母膏 }(2: 1) ; \mathrm{M}: \text { 蛋白胨+牛肉膏 }(2: 1) ; \mathrm{N}: \text { 蛋白胨+酵母粉 } \\
(2: 1) ; \mathrm{O} \text { 胰蛋白胨+酵母粉 }(2: 1) ; \mathrm{P}: \text { 胰蛋白胨+酵母膏 }(2: 1)\end{array}$ \\
\hline 无机盐 & A: 氯化钠; B: 氯化钾; C: 无水氯化钻; D: 磷酸二氢钾; E: 磷酸氢二钾; F: 柠檬酸钠 \\
\hline 金属离子 & A: 氯化铁; B: 硫酸镁; C: 硫酸锰; D: 硫酸锌; E: 硫酸亚铁; F: 硫酸钴; G: 硫酸镍; H: 硫酸铜 \\
\hline
\end{tabular}


表 4 正交实验设计表

Table 4 Table of orthogonal test design

\begin{tabular}{|c|c|c|c|c|c|c|}
\hline \multirow{2}{*}{ 水平 } & \multicolumn{6}{|c|}{ 因素 $(\mathrm{g} / \mathrm{L})$} \\
\hline & A蔗糖 & B酵母膏 & $\mathrm{C}$ 蛋白胨 & $\mathrm{D}$ 磷酸二氢钾 & E硫酸锰 & F硫酸镁 \\
\hline 1 & 20 & 20 & 10 & 2 & 1 & 4 \\
\hline 2 & 30 & 30 & 20 & 4 & 2 & 6 \\
\hline 3 & 40 & 40 & 30 & 6 & 3 & 8 \\
\hline
\end{tabular}

色谱条件: 色谱柱: HP-5石英毛细管柱 $30 \mathrm{~m} \times 0.25$ $\mathrm{mm} \times 0.25 \mu \mathrm{m}$; 进样口温度: $280^{\circ} \mathrm{C}$, 载气: 氢气; 载气流 速: $1.5 \mathrm{~mL} / \mathrm{min}$; GC进样方式: 分流进样, 分流比 $1: 20$; 升温程序：初始温度 $40^{\circ} \mathrm{C}$, 保持 $2 \mathrm{~min}$, 以升温速度 $20^{\circ} \mathrm{C} / \mathrm{min}$ 升温至 $280^{\circ} \mathrm{C}$, 保持 $5 \mathrm{~min}$.

\section{2 结果和分析}

\section{1 有机磷水解酶的笁选}

按照 1.3 的方法，评价酶液对神经毒剂模拟剂 DMMP的消毒效果, 由图1可知, 重组菌pHY-ZL-ob3对 DMMP的降解效果最好，达到 $38 \%$ ，因此选择ob3酶基 因作为本实验的研究对象.

\section{2 磷酸三酯酶基因在B. subtilis WB600中的表达}

（1）B. subtilis WB600表达载体的构建. 按1.2的方 法构建重组枯草芽孢杆菌表达载体，将测序正确的 pMD19-T-ob3经限制性内切酶EcoR I / Kpn I 双切后与 经相同酶切的载体 $\mathrm{pHY}-\mathrm{ZL}$ 连接, 转化B. subtilis WB600后挑取转化子，提取质粒进行酶切验证，双酶 切验证如图2所示. 由图2可知，提取质粒进行酶切验 证后得到了约 6.7 和 $1.0 \mathrm{kD}$ 大小的片段, 说明表达载体 pHY-ZL-ob3构建成功.

（2）有机磷水解酶基因在 B. subtilis WB600中的分 泌表达. 按 1.5 小节的方法发酵培养重组菌B. subtilis WB600/pHY-ZL-ob3, 离心得到粗酶液, 为了进一步研 究重组枯草芽狍杆菌蛋白的表达情况，对磷酸三酯酶 进行分离纯化. 由图3可知，在SDS-PAGE上显示单一 条带, 大小约为 $46 \mathrm{kD}$, 重组蛋白分子量与氨基酸序列 计算的理论蛋白大小 $(43.6 \mathrm{kD})$, 基本一致.

\section{3 摇瓶培养基的优化}

(1) 培养基碳源对重组菌产酶的而影响. 按照方法

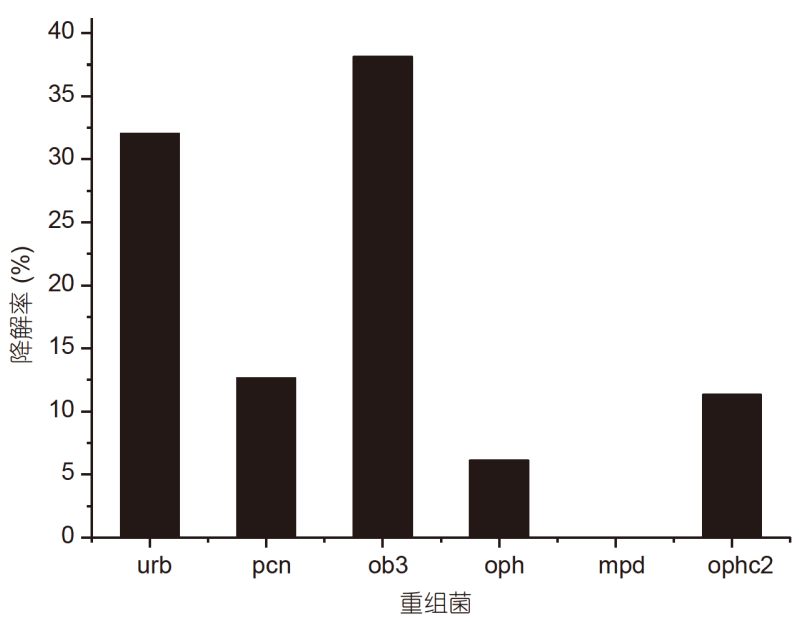

图 1 重组枯草芽孢杆菌对DMMP的降解效果

Figure 1 Degradation of DMMP by recombinant Bacillus subtilis

1.5 进行摇瓶发酵, $20 \mathrm{~h}$ 后测定酶活和 $A_{600}$, 以蔗糖为碳 源时的酶活力为 $100 \%$, 碳源对重组菌生长和产酶的影 响如图4所示. 当培养基中加入的碳源为蔗糖时，重组 菌的酶活水平最高, 达到 $0.55 \pm 0.04 \mathrm{U} / \mathrm{mL}$, 其他碳源如 马铃薯淀粉、可溶性淀粉、敖皮、糊精等酶活力未达 到蔗糖为碳源的 $50 \%$, 说明在所有碳源中, 蔗糖最有利 于重组菌的产酶. 因此, 选择蔗糖为最佳碳源. 蔗糖浓 度对酶活性的影响如图5所示，以蔗糖浓度为 $2.5 \%$ 时 的酶活力作为 $100 \%$, 蔗糖浓度较低时, 酶活性和菌体 生物量均较低, 随着蔗糖浓度的升高, 酶活性在蔗糖浓 度为 $2.5 \%$ 时达到最高, 为 $0.74 \pm 0.05 \mathrm{U} / \mathrm{mL}$. 因此, 选择 蔗糖的最佳浓度为 $2.5 \%$.

(2) 培养基氮源对重组菌产酶的而影响. 按照方法 1.5 进行摇瓶发酵, $20 \mathrm{~h}$ 后测定酶活和 $A_{600}$, 以复合氮源 为蛋白胨+酵母膏 $(\mathrm{L})$ 时的酶活力为 $100 \%$, 氮源对重组 菌生长和产酶的影响如图6所示。无机氮源硫酸铵 $(F)$ 、硝酸钾 $(G)$ 、复合氮源蛋白胨 + 硫酸铵 $(H)$ 和复合 氮源蛋白炼+硝酸钾 $(\mathrm{I})$ 对菌体的生长和产酶效果较差, 


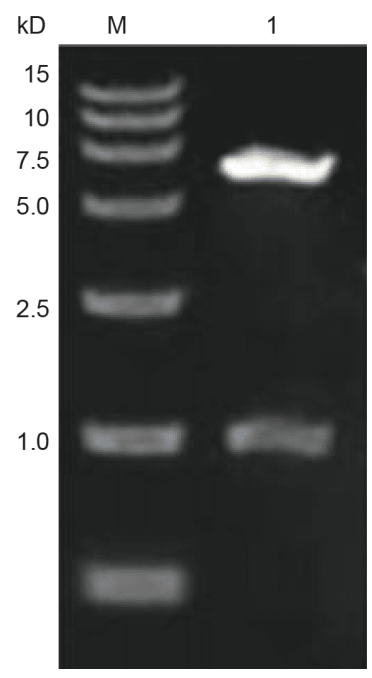

图 2 pHY-ZL-ob3 重组质粒酶切验证. M: DNA Marker; 1:

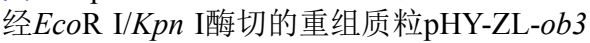

Figure 2 Restriction analysis of recombinant plasmids PHY-ZL-ob3. M: marker; 1: recombinant plasmids PHY-ZL-ob3 restricted by EcoR I and $\mathrm{Kpn}$ I

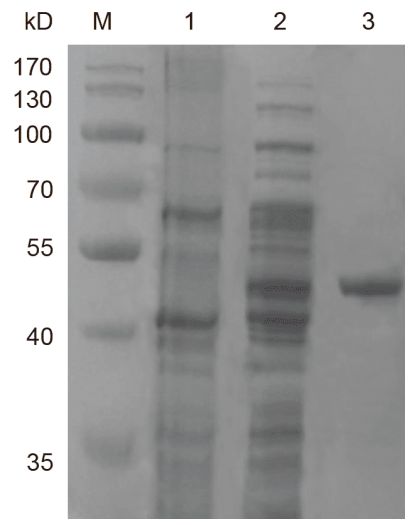

图 3 重组菌B. subtilis/pHY-ZL-ob3表达产物的SDS-PAGE 分析. M: marker; 1: 空载B. subtilis/pHY-ZL; 2: B. subtilis/ pHY-ZL-ob3发酵液上清; 3: B. subtilis/pHY-ZL-ob3纯化后的 重组蛋白

Figure 3 SDS-PAGE analysis of the expression product in recombinant strain. M: Protein marker; 1: B. subtilis/PHY-ZL; 2: fermentation supernatant of recombinant strain; 3: purification of $B$. subtilis/PHY-ZL$o b 3$

单一的有机氮源中酵母粉 $(\mathrm{E})$ 最有利于菌体的生长和 产酶. 但是与复合氮源相比, 复合氮源菌体的生长和产 酶量明显优于单一氮源, 达到 $1.22 \pm 0.07 \mathrm{U} / \mathrm{mL}$, 所以选 择蛋白炼+酵母膏 $(\mathrm{L})$ 为发酵培养基的最佳氮源; 同时 对蛋白胨与酵母膏的添加比例进行优化，如图7所示, 蛋白胨与酵母膏的比例为 $1: 5$ 时酶活力达到最高, 因此 选择蛋白胨与酵母膏的最佳添加比例为 $1: 5$. 以氮源浓

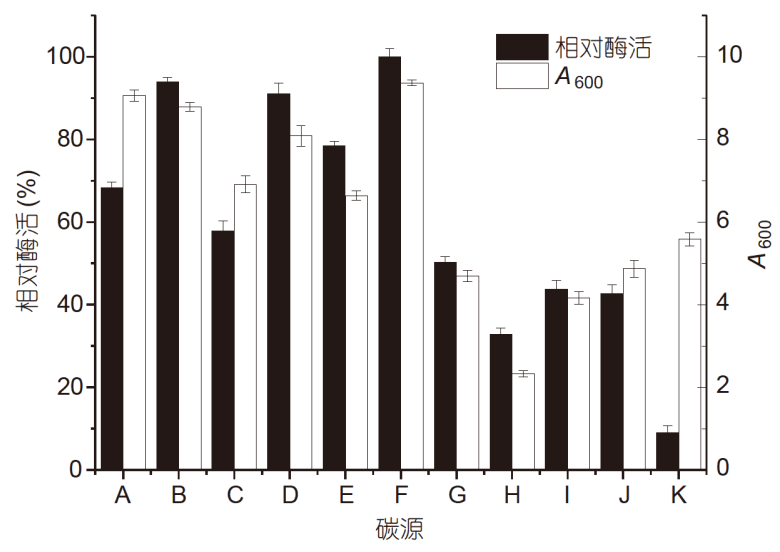

图 4 不同碳源对菌体产酶的影响. A: 甘油; B: 葡萄糖; C: 半乳糖; D: 乳糖; E: 麦芽糖; F: 蔗糖; G: 玉米粉; H: 可溶性淀 粉; I: 敖皮; J: 马铃薯淀粉; K: 糊精

Figure 4 Effect of different carbon sources on PTE production. A: Glycerol; B: glucose; C: galactose; D: lactose; E: maltose; F: sucrose; G: corn meal; H: soluble starch; I: bran; J: potato starch; K: dextrin

度为 $4 \%$ 时的酶活力为 $100 \%$, 氮源浓度对菌体生长和 酶活力的影响如图 8 所示，氮源浓度为 $4 \%$ 时酶活力最 高, 达到 $1.45 \pm 0.13 \mathrm{U} / \mathrm{mL}$, 氮源浓度高于 $4 \%$ 时, 产酶不 再增加, 因此, 选择氮源浓度为 $4 \%$.

(3) 培养基无机盐对重组菌产酶的而影响. 无机盐 如硫酸镁、磷酸二氢钾等主要参与一些酶的组成成 分, 对维持酶的活性等有重要作用 ${ }^{[27]}$. 按照方法1.5进 行摇瓶发酵, $20 \mathrm{~h}$ 后测定酶活和 $A_{600}$, 以未加无机盐时 的酶活力为 $100 \%$, 无机盐对重组菌生长和产酶的影响 如图9所示. 磷酸二氢钾对酶活力有促进作用, 其他无 机盐对酶活的影响不显著. 无机盐浓度对酶活的影响 如图10所示, $\mathrm{KH}_{2} \mathrm{PO}_{4}$ 的浓度为 $4 \mathrm{~g} / \mathrm{L}$ 时酶活达到最高, 达到 $1.87 \pm 0.35 \mathrm{U} / \mathrm{mL}$ ，浓度高于 $4 \mathrm{~g} / \mathrm{L}$ 时，产酶不再增 加. 因此, 选择 $\mathrm{KH}_{2} \mathrm{PO}_{4}$ 的浓度为 $4 \mathrm{~g} / \mathrm{L}$.

(4) 不同金属离子对重组菌产酶的影响. 按照方法 1.5 进行摇瓶发酵, $20 \mathrm{~h}$ 后测定酶活和 $A_{600}$, 以未加金属 离子时的酶活力为 $100 \%$, 金属离子对重组菌生长和产 酶的影响如图11所示. 其中 $\mathrm{Mg}^{2+}(\mathrm{B}), \mathrm{Mn}^{2+}(\mathrm{C})$ 对菌体产 酶有促进作用，分别提高了约 $10 \%$ 和 $20 \%$ 的酶活. $\mathrm{Fe}^{2+}$ (E)对产酶有抑制作用, $\mathrm{Zn}^{2+}(\mathrm{D}), \mathrm{Co}^{2+}(\mathrm{F}), \mathrm{Ni}^{2+}(\mathrm{G}), \mathrm{Cu}^{2+}$ $(\mathrm{H})$ 抑制重组菌的生长. 由图12可知, $\mathrm{Mn}^{2+}$ 浓度为 $2 \mathrm{~g} / \mathrm{L}$ 时酶活最高, 磷酸三酯酶的酶活力达到 $1.92 \pm 0.12 \mathrm{U} /$ $\mathrm{mL}$, 由图13可知, $\mathrm{Mg}^{2+}$ 浓度为 $4 \mathrm{~g} / \mathrm{L}$ 时酶活最高, 磷酸 三酯酶的酶活力达到 $2.08 \pm 0.24 \mathrm{U} / \mathrm{mL}$, 所以选择 $\mathrm{Mn}^{2+}$ 


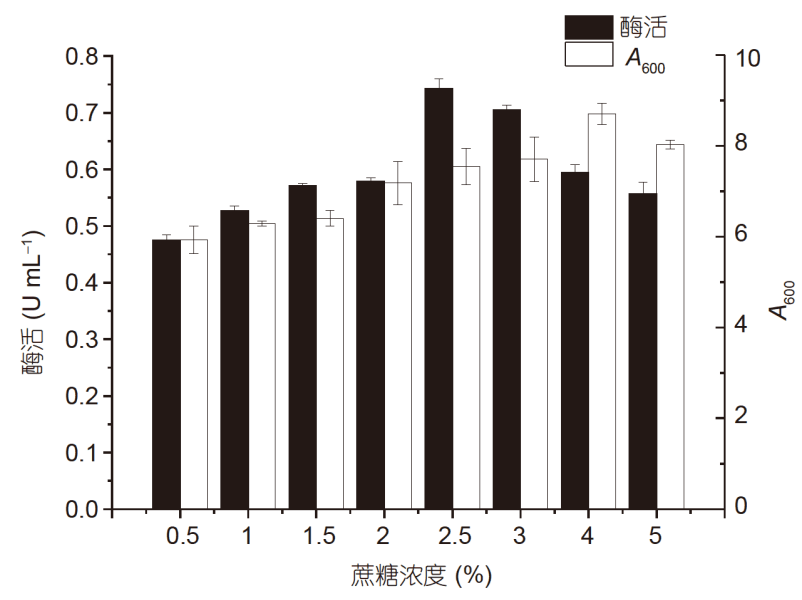

图 5 碳源浓度对菌体产酶的影响

Figure 5 Effect of carbon source concentration on PTE production

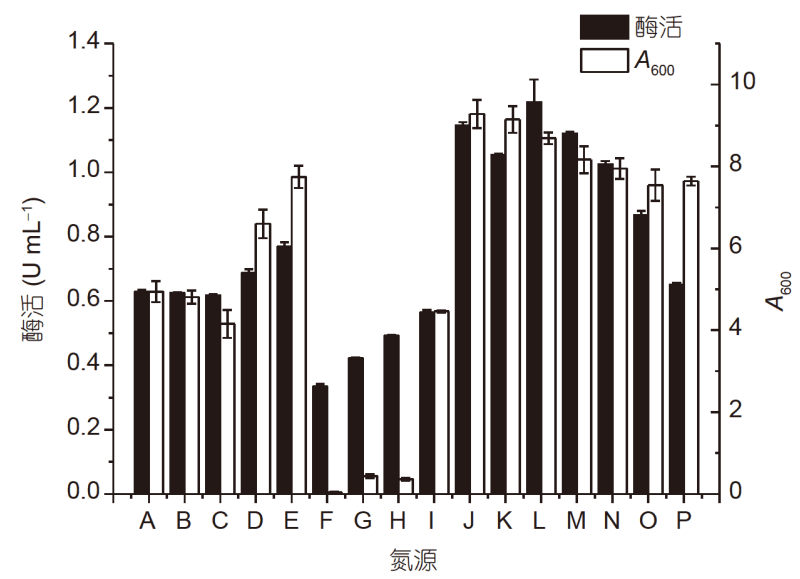

图 6 不同氮源对菌体产酶的影响. A: 蛋白炼; B: 胰蛋白炼; C: 牛肉膏; D: 酵母膏; E: 酵母粉; F: 硫酸铵; G: 硝酸钾; H: 蛋白胨+硫酸铵 $(2: 1)$; I: 蛋白胨+硝酸钾 $(2: 1)$; J: 酵母粉+硫酸 铵 $(2: 1) ; \mathrm{K}$ : 酵母粉+硝酸钾 $(2: 1) ; \mathrm{L}$ : 蛋白胨+酵母膏 $(2: 1) ; \mathrm{M}$ : 蛋白胨+牛肉膏 $(2: 1) ; \mathrm{N}$ : 蛋白胨+酵母粉 $(2: 1) ; \mathrm{O}$ : 胰蛋白胨 +酵母粉 $(2: 1)$; P: 胰蛋白胨+酵母膏 $(2: 1)$

Figure 6 Effects of different nitrogen sources on PTE production. A: Peptone; B: tryptone; C: extractum carnis; D: yeast extract; E: yeast powder; F: ammonia sulfate; G: potassium nitrate; $\mathrm{H}$ : peptone +ammonia sulfate (2:1); I: peptone+POTASSIUM nitrate (2:1); J: yeast powder+ammonia sulfate $(2: 1) ; \mathrm{K}$ : yeast powder+potassium nitrate (2:1); L: peptone+yeast extract (2:1); M: peptone+extractum carnis $(2: 1)$; N: peptone+yeast powder $(2: 1)$; O: tryptone+yeast powder $(2: 1)$; P: tryptone+yeast extract $(2: 1)$

浓度为 $2 \mathrm{~g} / \mathrm{L}, \mathrm{Mg}^{2+}$ 浓度为 $4 \mathrm{~g} / \mathrm{L}$.

(5) 正交实验结果. 以蔗糖为碳源因素, 酵母膏和 蛋白胨为氮源因素, 磷酸二氢钾为无机盐因素, 硫酸镁 和硫酸锰为金属离子因素. 由实验结果(表5)的极差大 小可知，对菌株产酶影响最大的是酵母膏，其次是蔗

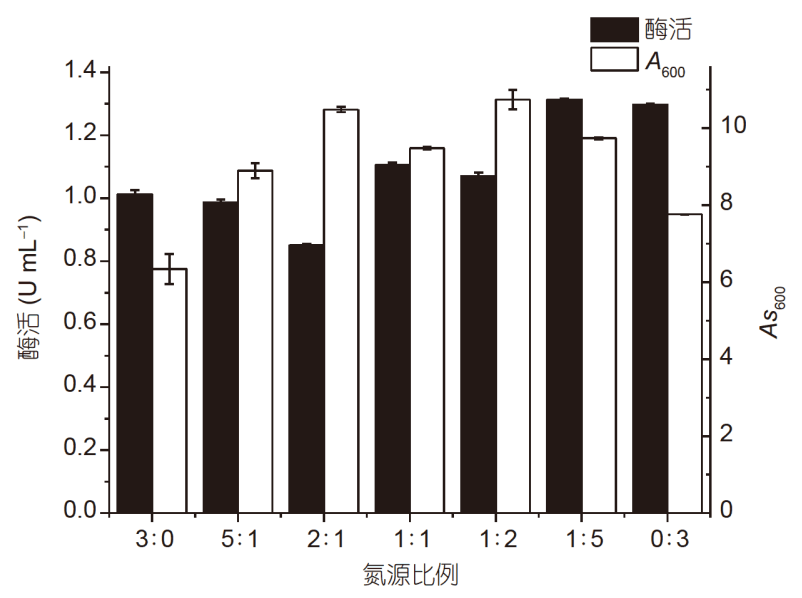

图 7 蛋白胨与酵母膏的比例对产酶的影响

Figure 7 Effect of proportion of nitrogen source on growth and PTE production

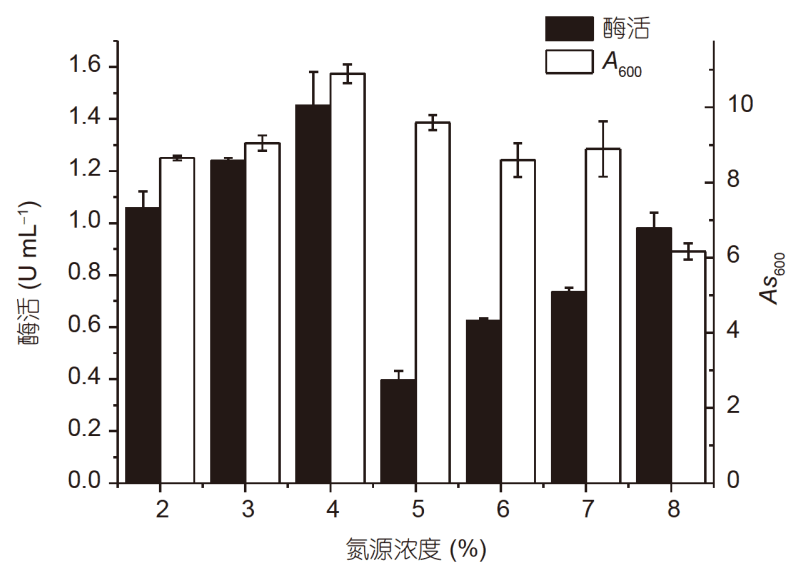

图 8 氮源浓度对重组菌产酶的影响

Figure 8 Effect of nitrogen source concentration on PTE production

糖、硫酸锰、蛋白胨、磷酸二氢钾、硫酸镁, 按照此 顺序，最优添加量依次为 $40,40,1,20,2,6 \mathrm{~g} / \mathrm{L}$. 使用 此培养基进行摇瓶发酵验证，实验设定 3 个平行，取其 平均值, 重组酶活可达到 $3.13 \pm 0.15 \mathrm{U} / \mathrm{mL}$.

\section{4 重组菌株培养基优化验证实验结果}

温度、转速等条件保持不变，分别采用优化前、 后的培养基进行对比实验，结果显示，在优化前、后 的培养基中培养 $20 \mathrm{~h}$,重组菌株 $A_{600}$ 分别为 6.13 和 18.45 , 优化后提高了 $33 \%$ ，重组酶活性分别为 0.45 和 3.13 $\mathrm{U} / \mathrm{mL}$. 因此, 最优的培养基组成为蔗糖 $40 \mathrm{~g} / \mathrm{L}$, 酵母膏 $40 \mathrm{~g} / \mathrm{L}$, 蛋白胨 $20 \mathrm{~g} / \mathrm{L}$, 磷酸氢二钾 $2 \mathrm{~g} / \mathrm{L}$, 硫酸锰 $1 \mathrm{~g} / \mathrm{L}$, 硫酸镁 $6 \mathrm{~g} / \mathrm{L}$. 


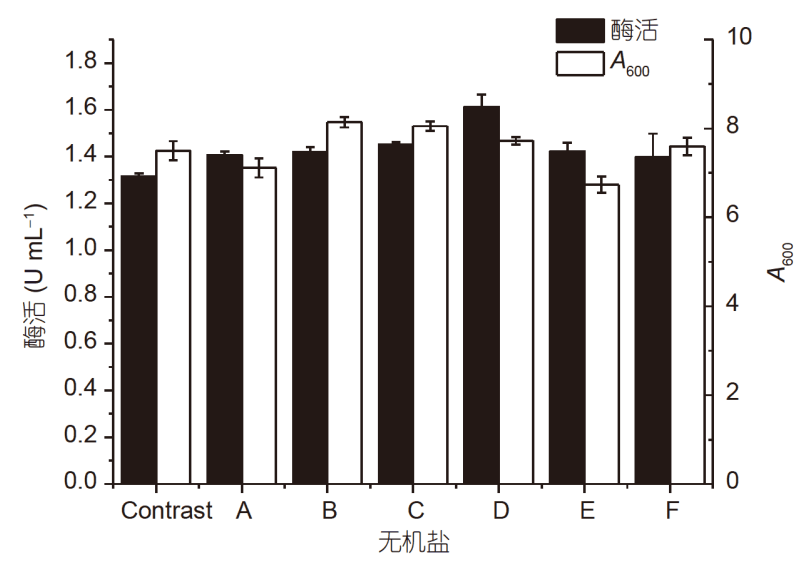

图 9 不同无机盐对菌体产酶的影响. A: 氯化钠; B: 氯化钾; C: 无水氯化钻; D: 磷酸二氢钾; E: 磷酸氢二钾; F: 三水柠檬 酸钠

Figure 9 Effects of different mineral salts on PTE production. A: $\mathrm{NaCl}$; B: KCl; C: $\mathrm{CaCl}_{2}$; D: $\mathrm{KH}_{2} \mathrm{PO}_{4} ; \mathrm{E}: \mathrm{K}_{2} \mathrm{HPO}_{4} ; \mathrm{F}: \mathrm{Na}_{3} \mathrm{C}_{6} \mathrm{H}_{5} \mathrm{O}_{7} \bullet 3 \mathrm{H}_{2} \mathrm{O}$

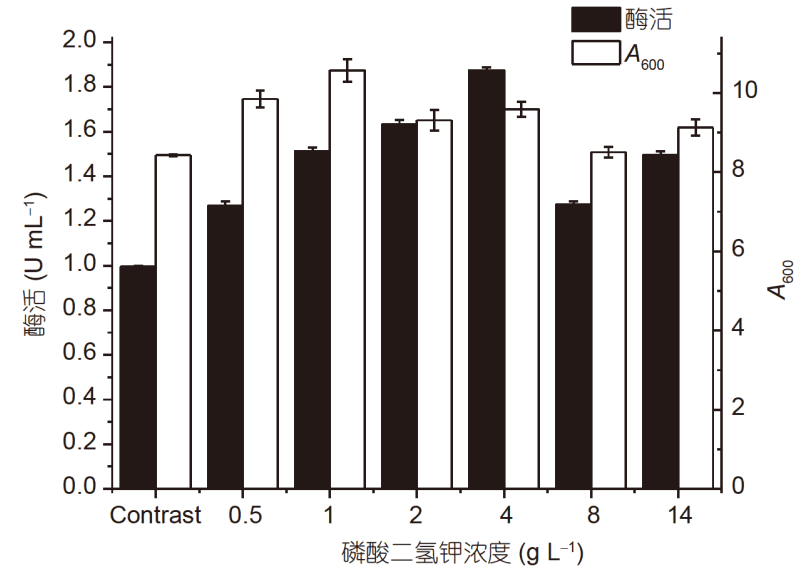

图 10 磷酸二氢钾浓度对重组菌产酶的影响

Figure 10 Effect of $\mathrm{KH}_{2} \mathrm{PO}_{4}$ concentration on PTE production

\section{5 重组酶对有机磷化合物降解率的测定}

按照 1.8 的方法测定重组酶对甲基对硫磷、乐 果、DMMP的降解率，如图14 16所示. 由图可知， $37^{\circ} \mathrm{C}$ ，反应 $30 \mathrm{~min}$ 后对甲基对硫磷的降解率达到 $62 \%$, 乐果的降解率达到 $48 \%$ ，反应 $2 \mathrm{~h}$ 后对DMMP的降解率 达到 $65 \%, 12 \mathrm{~h}$ 后对甲基对硫磷、乐果、DMMP的降 解率达到 $99.8 \%, 96.7 \%, 90.4 \%$.

\section{3 讨论}

有机磷农药在我国使用量大，易于在土壤中短时

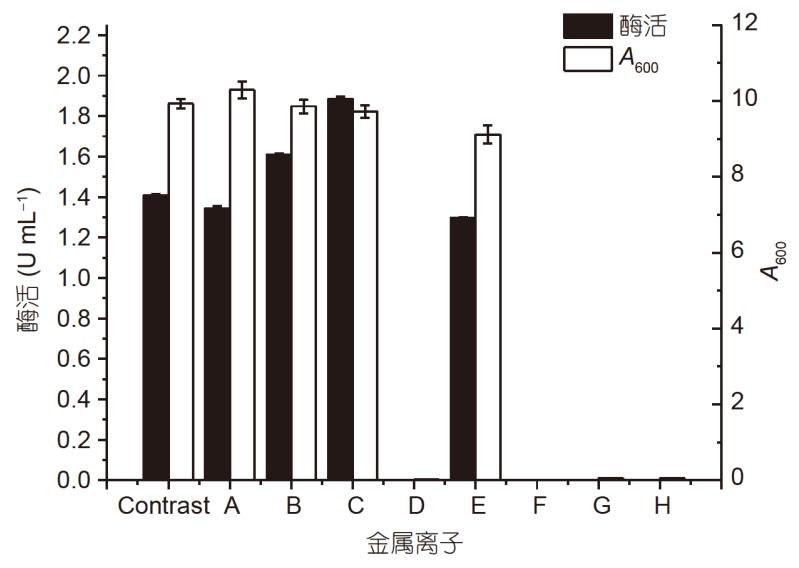

图 11 不同金属离子对重组菌产酶的影响. $\mathrm{A}$ : 氯化铁; B: 硫酸镁; C: 硫酸锰; D: 硫酸锌; E: 硫酸亚铁; F: 硫酸钴; G: 硫 酸镍; $\mathrm{H}$ : 硫酸铜

Figure 11 Effect of different metal ions on PTE production. A: $\mathrm{FeCl}_{3}$; B: $\mathrm{MgSO}_{4} ; \mathrm{C}: \mathrm{MnSO}_{4} ; \mathrm{D}: \mathrm{ZnSO}_{4} ; \mathrm{E}: \mathrm{FeSO}_{4} ; \mathrm{F}: \mathrm{CoSO}_{4} ; \mathrm{G}: \mathrm{NiSO}_{4} ; \mathrm{H}$ : $\mathrm{GuSO}_{4}$

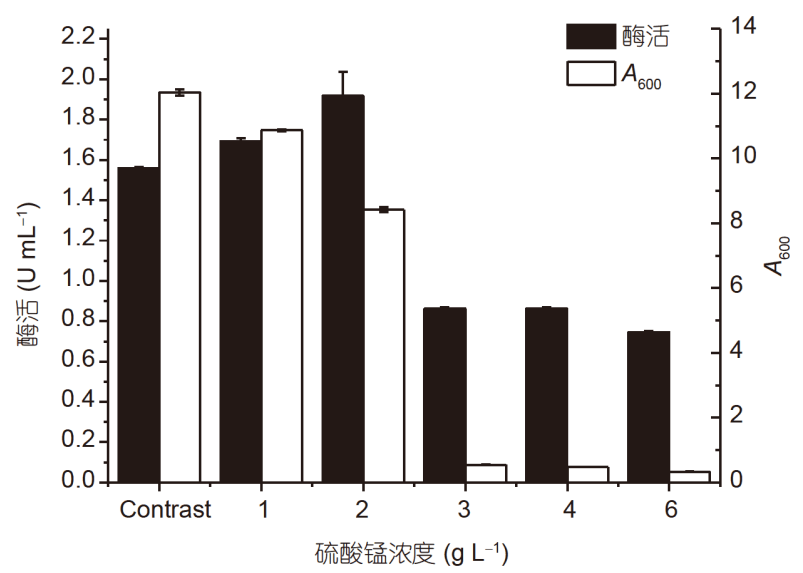

图 $12 \mathrm{Mn}^{2+}$ 对重组菌产酶的影响

Figure 12 Effect of $\mathrm{Mn}^{2+}$ concentration on PTE production

间内积累，并在生物体内蓄积，对人类健康和环境都 有极大的危害 ${ }^{[28]}$. 生物酶具有效率高、环境友好等优 点，能够以氧化、水解等方式降解有机磷类化合物， 已逐渐成为降解有机磷农药的主要材料. 目前，国内 对有机磷水解酶的研究主要集中于降解有机磷杀虫 剂, 对有机磷神经毒剂研究较少, 且大多需要诱导, 操 作流程繁琐。2018年，王颖等人 ${ }^{[29]}$ 对有机磷水解酶 (opd)进行密码子优化，通过优化后的基因和生物砖方 法构建多拷贝载体以提高在毕赤酵母中的表达量. 实 验结果表明，甲醇诱导后，在AOX1(乙醇氧化酶基因) 启动子调控下, OPD P蛋白获得胞外分泌表达, 酶活达 


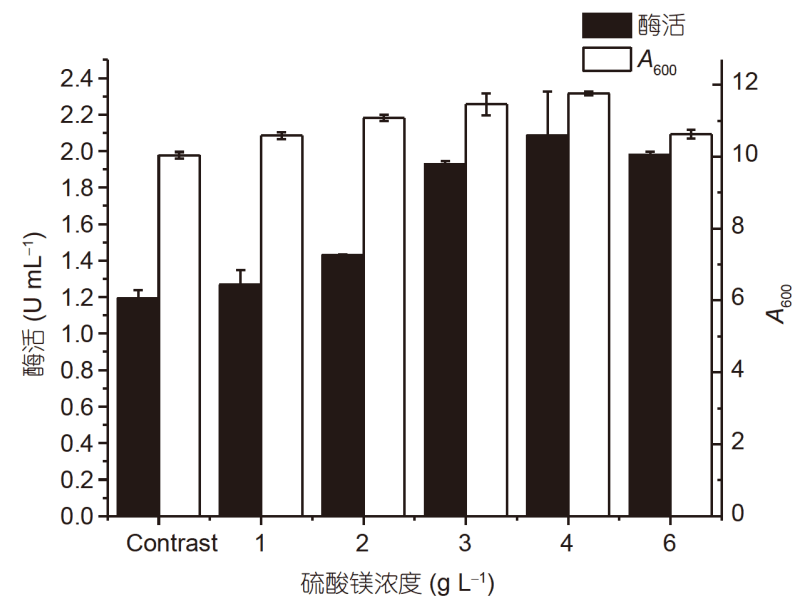

图 $13 \mathrm{Mg}^{2+}$ 对重组菌产酶的影响

Figure 13 Effect of $\mathrm{Mg}^{2+}$ concentration on PTE production

到0.2 U/mL. 2017年, 肖运柱等人 ${ }^{[30]}$ 发现, OPAA4301, 一种源自海洋细菌的有机磷酸酐水解酶, 可以少量分
泌到培养基上清液中，进一步优化后，胞外酶活提高 108.8 倍, 达0.28 U/mL. 由此可见, 有机磷降解酶活性 低、表达量低、催化效率低等问题依然存在. 因此, 建 立一种有机磷降解酶的高效表达体系是迫切需要解决 的问题. 本文构建了PTE基因来源于缺陷假单胞菌 (Pseudomonas diminuta)的重组枯草芽狍杆菌(Bacillus subtilis WB600), 并采用单因素实验和正交实验对培 养基进行优化，确定了重组菌产酶的最佳发酵条件. 结果表明, 在优化前、后的培养基中培养 $20 \mathrm{~h}$, 重组菌 株 $A_{600}$ 分别为 6.13 和 18.45 , 优化后提高了 2 倍, 重组酶 活性分别为 0.45 和 $3.13 \mathrm{U} / \mathrm{mL}$ ，优化后酶活提高了约 6 倍, 所得最优培养基组成为蔗糖 $40 \mathrm{~g} / \mathrm{L}$, 酵母膏 $40 \mathrm{~g} / \mathrm{L}$, 蛋白胨 $20 \mathrm{~g} / \mathrm{L}$, 磷酸氢二钾 $2 \mathrm{~g} / \mathrm{L}$, 硫酸锰 $1 \mathrm{~g} / \mathrm{L}$, 硫酸镁 $6 \mathrm{~g} / \mathrm{L}$. 部分解决了一直以来困扰有机磷水解酶表达量 低、活性低的问题.

微生物可以通过氧化、还原、脱氢、合成、水解

表 5 产酶实验正交结果表

Table 5 Results of orthogonal test

\begin{tabular}{|c|c|c|c|c|c|c|c|c|}
\hline 实验 & A蔗糖 & B酵母膏 & C蛋白胨 & D磷酸二氢钾 & E硫酸锰 & F硫酸镁 & G空列 & 酶活 $(\mathrm{U} / \mathrm{mL})$ \\
\hline 1 & 1 & 1 & 1 & 1 & 1 & 1 & 1 & 0.68 \\
\hline 2 & 1 & 2 & 2 & 2 & 2 & 2 & 2 & 0.96 \\
\hline 3 & 1 & 3 & 3 & 3 & 3 & 3 & 3 & 1.26 \\
\hline 4 & 2 & 1 & 1 & 2 & 2 & 3 & 3 & 0.77 \\
\hline 5 & 2 & 2 & 2 & 3 & 3 & 1 & 1 & 1.68 \\
\hline 6 & 2 & 3 & 3 & 1 & 1 & 2 & 2 & 1.85 \\
\hline 7 & 3 & 1 & 2 & 1 & 3 & 2 & 3 & 2.20 \\
\hline 8 & 3 & 2 & 3 & 2 & 1 & 3 & 1 & 1.99 \\
\hline 9 & 3 & 3 & 1 & 3 & 2 & 1 & 2 & 2.24 \\
\hline 10 & 1 & 1 & 3 & 3 & 2 & 2 & 1 & 2.16 \\
\hline 11 & 1 & 2 & 1 & 1 & 3 & 3 & 2 & 2.54 \\
\hline 12 & 1 & 3 & 2 & 2 & 1 & 1 & 3 & 2.83 \\
\hline 13 & 2 & 1 & 2 & 3 & 1 & 3 & 2 & 1.22 \\
\hline 14 & 2 & 2 & 3 & 1 & 2 & 1 & 3 & 1.56 \\
\hline 15 & 2 & 3 & 1 & 2 & 3 & 2 & 1 & 1.78 \\
\hline 16 & 3 & 1 & 3 & 2 & 3 & 1 & 2 & 1.61 \\
\hline 17 & 3 & 2 & 1 & 3 & 1 & 2 & 3 & 1.82 \\
\hline 18 & 3 & 3 & 2 & 1 & 2 & 3 & 1 & 2.12 \\
\hline $\mathrm{K} 1$ & 1.738 & 1.440 & 1.638 & 1.825 & 1.732 & 1.767 & 1.735 & \\
\hline $\mathrm{K} 2$ & 1.477 & 1.758 & 1.835 & 1.657 & 1.635 & 1.795 & 1.737 & \\
\hline $\mathrm{K} 3$ & 1.997 & 2.013 & 1.738 & 1.730 & 1.845 & 1.650 & 1.740 & \\
\hline $\mathrm{R}$ & 0.520 & 0.573 & 0.197 & 0.168 & 0.210 & 0.145 & 0.005 & \\
\hline
\end{tabular}




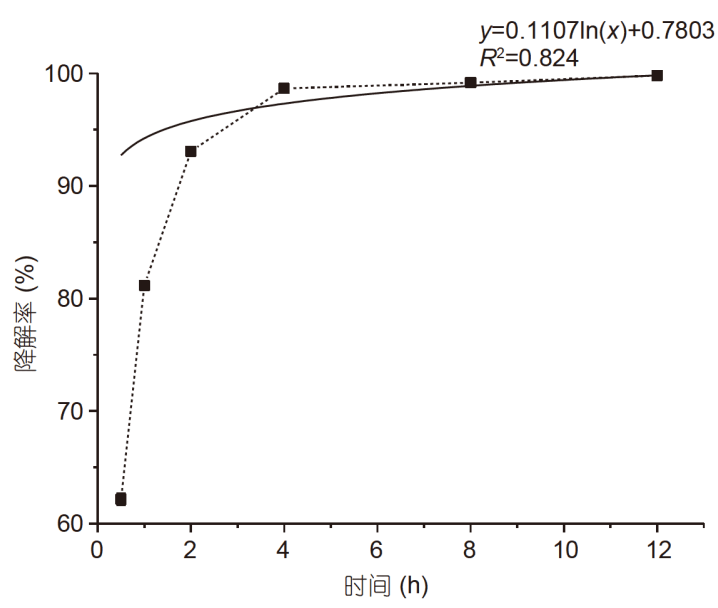

图 14 PTE降解甲基对硫磷的生物转化曲线

Figure 14 Bioconversion curve of parathion-methyl degradation by PTE

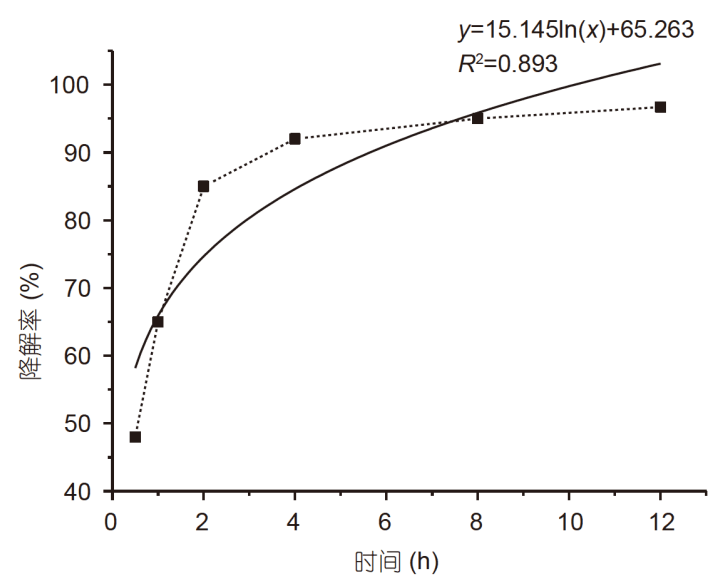

图 15 PTE降解乐果的生物转化曲线

Figure 15 Bioconversion curve of dimethoate degradation by PTE

等作用直接作用于有机磷化合物将其降解. Liu等人 ${ }^{[31]}$ 在分离得到的抗辐射不动杆菌USTB-04降解甲基对硫 磷的过程中, 没有发现任何中间产物和最终产物, 他推 测出USTB-04首先促使苯环上的 C-C键发生断裂而非 作用于 $\mathrm{P}=\mathrm{O}$ 键. 李松桧 ${ }^{[32]}$ 从污泥中分离出一株以共代

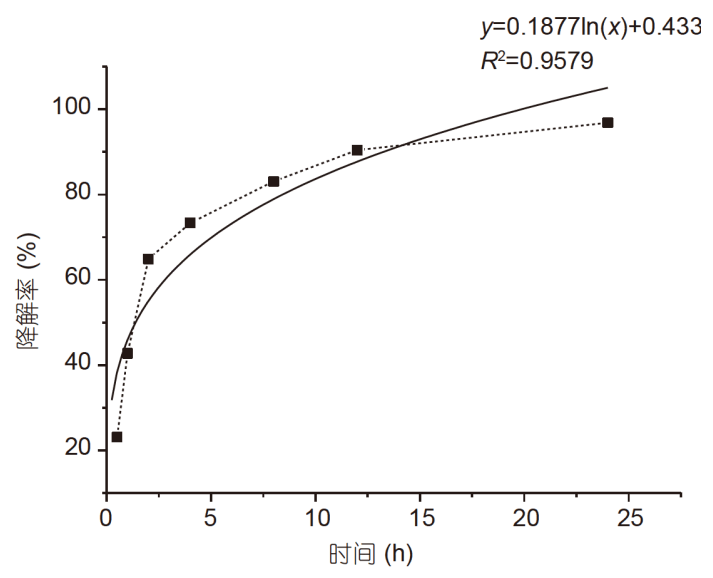

图 16 PTE降解DMMP毒剂的生物转化曲线

Figure 16 Bioconversion curve of DMMP degradation by PTE

谢方式降解氧乐果的菌株YB-10, 对乐果的降解率达 $73.81 \%$. 本研究利用自主建立的枯草芽孢表达系统将 外源基因插入到含有信号肽的载体上，使得表达的外 源蛋白能够分泌到发酵液上清中，不需破壁、不需诱 导就可以得到酶蛋白，简化了酶蛋白的后加工工艺， 解决了在大肠杆菌中表达产生的包涵体问题，有利于 酶蛋白的规模化生产. 重组酶反应 $30 \mathrm{~min}$ 就可对甲基 对硫磷和乐果达到 $50 \%$ 的降解率，反应 $2 \mathrm{~h}$ 后对神经毒 剂模拟剂DMMP的降解率达到 $65 \%, 4 \mathrm{~h}$ 内对 $5 \mathrm{mg} / \mathrm{mL}$ 的甲基对硫磷、乐果以及DMMP的降解率分别达到 $98 \%, 92 \%, 73 \%$, 且DMMP在 $12 \mathrm{~h}$ 内也完全降解. 本研 究篮选表达的PTE对乐果、甲基对硫磷、DMMP均有 较好的降解效果. 由于有机磷化合物具有相似的分子 结构, 所以推测该重组酶对有机磷化合物具有一定的 广谱性. 而PTE对DMMP的降解较甲基对硫磷、乐果 的速率慢，推测是由于不同化合物构象不同，且不同 的微生物降解不同的有机磷化合物所断裂的键有所不 同所引起的结果. 后续将运用分子定向进化技术, 进一 步寻找良性突变体, 在分子水平上改善酶的性质.

\section{参考文献}

1 Zhang Y. Molecular evolution of a thermostable phosphotriesterase-like lactonase toward high degradation (in Chinese). Dissertation for Doctoral Degree. Jilin: Jilin Univ, 2012. 1-1152 [张宇. 嗜热类磷酸三酯酶的内酯酶分子进化以提高对有机磷杀虫剂的降解活力. 博士学位论文. 吉 林: 吉林大学, 2012. 1-1152]

2 Bai H H. Methodologies on the detction of Nerve Agents (in Chinese). Dissertation for Master's Degree. Beijing: Acad Military Med Sci, 2008. 1-82 [白海红. 神经性毒剂分析检测方法的研究. 硕士学位论文. 北京: 中国人民解放军军事医学科学院, 2008. 1-82] 
3 Bigley A N, Mabanglo M F, Harvey S P, et al. Variants of phosphotriesterase for the enhanced detoxification of the chemical warfare agent VR. Biochemistry, 2015, 54: 5502-5512

4 Kirby S D, Norris J R, Richard Smith J, et al. Human paraoxonase double mutants hydrolyze V and G class organophosphorus nerve agents. Chem Biol Interact, 2013, 203: 181-185

5 Melzer M, Chen J C H, Heidenreich A, et al. Reversed enantioselectivity of diisopropyl fluorophosphatase against organophosphorus nerve agents by rational design. J Am Chem Soc, 2009, 131: 17226-17232

6 Zhou Y, Zhang B, Lin Z J, et al. Virtual screening for components in Chicory combined with CNT2 target based on molecular docking (in Chinese). Chin J Chin Mater Med, 2016, 41: 3962-3967 [周月, 张冰, 林志健, 等. 基于分子对接技术虚拟筛选菊苣与肠道CNT2结合的化学 成分研究. 中国中药杂志, 2016, 41: 3962-3967]

7 Campbell E, Kaltenbach M, Correy G J, et al. The role of protein dynamics in the evolution of new enzyme function. Nat Chem Biol, 2016, 12: 944-950

8 Tsai P C, Fox N, Bigley A N, et al. Enzymes for the homeland defense: optimizing phosphotriesterase for the hydrolysis of organophosphate nerve agents. Biochemistry, 2012, 51: 6463-6475

9 Benning M M, Shim H, Raushel F M, et al. High resolution X-ray structures of different metal-substituted forms of phosphotriesterase from Pseudomonas diminuta. Biochemistry, 2001, 40: 2712-2722

10 Guo N, Zhong J Y, Chen S L, et al. Experimental and theoretical studies of hydrolysis of nerve agent sarin by binuclear zinc biomimetic catalysts. Chem Phys, 2015, 457: 70-77

11 Porowińska D, Wujak M, Roszek K, et al. Prokaryotic expression systems. Postepy Hig Med Dosw, 2013, 67: 119-129

12 Yang J, Yang C, Qiao C. Overexpression of protein disulfide isomerase DsbA enhanced detoxification of organophosphates and enhanced detectability in the environment following degradation of pesticide residues. World J Microbiol Biotechnol, 2011, 27: 785-790

13 Wen X F, Yuan Y Z, Xi H L, et al. Characteristics of a novel organophosphorus pesticide-degrading enzyme on diisopropyl fluorophosphates (in Chinese). J Central China Normal Univ, Nat Sci Ed, 2013, 47: 53-56 [问县芳, 袁永泽, 习海玲, 等. 一种新型有机磷降解酶的二异丙基氟磷酸 酯水解特性研究. 华中师范大学学报(自然科学版), 2013, 47: 53-56]

14 Sahdev S, Khattar S K, Saini K S. Production of active eukaryotic proteins through bacterial expression systems: a review of the existing biotechnology strategies. Mol Cell Biochem, 2008, 307: 249-264

15 Schiffrin B, Calabrese A N, Higgins A J, et al. Effects of periplasmic chaperones and membrane thickness on bama-catalyzed outer-membrane protein folding. J Mol Biol, 2017, 429: 3776-3792

16 Sonoda H, Kumada Y, Katsuda T, et al. Effects of cytoplasmic and periplasmic chaperones on secretory production of single-chain Fv antibody in Escherichia coli. J Biosci Bioeng, 2011, 111: 465-470

17 Wang R, Xiang S, Feng Y, et al. Engineering production of functional scFv antibody in E. coli by co-expressing the molecule chaperone Skp. Front Cell Infect Microbiol, 2013, 3

18 Gong P, Fan J Y, Tian J, et al. Effects of thermal stability on secretion of methyl-parathion hydrolase in Pichia pastoris (in Chinese). Agric Sci Tech China, 2015, 17: 42-48 [龚攀, 范家佑, 田健, 等. 热稳定性对甲基对硫磷水解酶在毕赤酵母中分泌的影响. 中国农业科技导报, 2015, 17: 42-48]

19 Giesübel U, Dälken B, Mahmud H, et al. Cell binding, internalization and cytotoxic activity of human granzyme B expressed in the yeast Pichia pastoris. Biochem J, 2006, 394: 563-573

20 Chang S W, Li C F, Lee G C, et al. Engineering the expression and biochemical characteristics of recombinant Candida rugosa LIP2 lipase by removing the additional N-terminal peptide and regional codon optimization. J Agric Food Chem, 2011, 59: 6710-6719

21 Cos O, Ramón R, Montesinos J L, et al. Operational strategies, monitoring and control of heterologous protein production in the methylotrophic yeast Pichia pastoris under different promoters: a review. Microb Cell Fact, 2006, 5: 17

22 Yu H, Yan X, Shen W, et al. Expression of methyl parathion hydrolase in Pichia pastoris. Curr Microbiol, 2009, 59: 573-578

23 Yang C, Song C, Freudl R, et al. Twin-arginine translocation of methyl parathion hydrolase in Bacillus subtilis. Environ Sci Technol, 2010, 44: $7607-7612$

24 Wu N, Deng M, Shi X, et al. Isolation, purification and properties characterization of a new organphosphorus hydrolase OPHC2. Chin Sci Bull, 2004, 49: 268

25 Xiao C, Zhang L, Li Y Y, et al. Heterologous expression, purification and characterization of phospholipase C from Bacillus cereus in 
Kluyveromyces lactis (in Chinese). Acta Microbiol Sin, 2017, 57: 87-96 [肖超, 张梁, 李颜颜, 等. 蜡样芽胞杆菌磷脂酶C在乳酸克鲁维酵母中 重组表达、纯化及酶学性质分析. 微生物学报, 2017, 57: 87-96]

26 Wang C X, Zhang J Q, Na S. Determination of four kinds of organic compounds in water quality standard by a gas chromatography system (in Chinese). Environ Chem, 2015, 34: 1569-1573 [王春晓, 张劲强, 那顺. 采用一台气相色谱系统检测水质标准中四类有机化合物. 环境化学, 2015, 34: 1569-1573]

27 Lv X, Duan Z Y, Mao G Z. Study on the effects of nitrogen sources and inorganic salts on ethanol fermentation (in Chinese). J Northwest A \& F univ, Nat Sci Ed, 2003, 31: 159-162 [吕欣, 段作营, 毛忠贵. 氮源与无机盐对高浓度酒精发酵的影响. 西北农林科技大学学报(自然科学版), 2003, 31: 159-162]

28 Li J Y, Wang X L, Zou Z R. The screening and advantage of degradation process optimization of acrylamide degradation bacterium (in Chinese). J Jiangxi Normal Univ, Nat Sci Ed, 2012, 1: 35-40 [李俊叶, 王篵兰, 邹峥嵘. 丙烯酰胺降解菌的筛选及优势菌株降解条件优化. 江西师范大 学学报(自然科学版), 2012, 1: 35-40]

29 Wang Y, Huang C, Sun Q M, et al. The expression of optimized and synthesized organic phosphorus hydrolase opd p gene in Pichia pastoris(in Chinese). J Hubei Univ, Nat Sci Ed, 2018, 40: 7-11+23 [王颖, 黄灿, 孙其濛, 等. 优化合成有机磷水解酶opd_p基因在毕赤酵母中的表达. 湖 北大学学报(自然科学版), 2018, 40: 7-11+23]

30 Xiao Y Z, Yang J, Zhang S, et al. Expression of a marine bacterial organophosphorus acid anhydrolase in Escherichia coli (in Chinese). Chin J Bioproc Eng, 2017, 15: 1-6 [肖运柱, 杨键, 张偲, 等. 海洋细菌有机磷酸酐水解酶在大肠杆菌中的分泌表达研究. 生物加工过程, 2017, 15: $1-6]$

31 Liu F, Hong M, Liu D, et al. Biodegradation of methyl parathion by Acinetobacter radioresistens USTB-04. J Environ Sci, 2007, 19: 1257-1260

32 Li S H. Study on isolation and breeding of omethoate-degrading strains and their growth and degradation characteristics (in Chinese). Shanxi: Shanxi Univ, 2008. 1-89 [李松桧. 氧乐果降解菌的分离选育、生长和降解特性研究. 山西: 山西大学, 2008. 1-89]

\title{
Recombinant expression and optimization of fermentation conditions of phosphotriesterase
}

\author{
YANG ZhenNi ${ }^{1}$, GUO Xuan ${ }^{2}$, ZHONG JinYi ${ }^{2}$, XIN Yu ${ }^{1}$, LI YouRan ${ }^{1}$, SHI GuiYang ${ }^{1} \&$ \\ ZHANG Liang $^{1}$
}
1 National Engineering Laboratory for Cereal Fermentation Technology, Key Laboratory of Industrial Biotechnology of Ministry of Education, Jiangnan University, Wuxi 214122, China;
2 Institute of Chemical Defense, Beijing 102205, China

Phosphotriesterase (PTE, EC 3.1.8.1) has been shown to hydrolyze organophosphorus compounds. However, its application has been limited by the low expression levels of enzymes. The purpose of the present study was to obtain highly expressed organophosphorus hydrolases. Recombinant Bacillus subtilis strains were developed to produce PTE from Pseudomonas diminuta. Single factor and orthogonal design experiments were used to optimize the broth. The enzymatic degradation efficiency of organophosphorus compounds with the recombinant enzyme was also determined. The results indicated that the optimal fermentation medium contained $40 \mathrm{~g} / \mathrm{L}$ sucrose, $40 \mathrm{~g} / \mathrm{L}$ yeast extract, $20 \mathrm{~g} / \mathrm{L}$ peptone, $2 \mathrm{~g} / \mathrm{L}$ dipotassium hydrogen phosphate, $1 \mathrm{~g} / \mathrm{L}$ manganese sulfate, and $6 \mathrm{~g} / \mathrm{L}$ magnesium sulfate. As determined, the enzymatic degradation rate of parathion-methyl, dimethoate, and a nerve agent analogue (dimethyl methyl phosphonate, DMMP) (5 mg/mL) were $98 \%, 92 \%$, and $73 \%$ under $4 \mathrm{~h}$ of biodegradation, respectively. In addition, the residual DMMP was completely degraded in $12 \mathrm{~h}$. In the present study, we achieved the extracellular secretion of PTE for the first time, which lays a foundation for the development of bio-enzyme-based decontaminants for organophosphorus compounds.

phosphotriesterase (PTE), Bacillus subtilis, fermentation condition optimization, organophosphorus compound, degradation rate

doi: $10.1360 / \mathrm{N} 052018-00237$ 